\title{
APPROXIMATION OF TIME FRACTIONAL BLACK-SCHOLES EQUATION VIA RADIAL KERNELS AND TRANSFORMATIONS
}

\author{
MARJAN UDDIN AND MUHAMMAD TAUFIQ
}

\begin{abstract}
In the present work, a numerical scheme is constructed for approximation of time fractional Black-Scholes model governing European options. The present numerical scheme has the capability to overcome spurious oscillation in the case of volatility. In the present numerical method, the Laplace transform, radial kernels and quadrature rule are used. The time variable is eliminated by the use of Laplace transform which significantly reduced the computational cost as compared to the time-marching schemes. The spatial operator is discretized using radial kernels in the local setting which results in sparse differentiation matrices. By Laplace transform the solution is represented as integral along a smooth contour in the complex plane which is then evaluated by quadrature. The proposed numerical scheme is used to price several different European options.
\end{abstract}

Mathematics subject classification (2010): 65M12, 65M15, 65M22.

Keywords and phrases: Local kernel based method, Black-Scholes model, contour integration, quadrature rule, PDEs.

\section{REFERENCES}

[1] D. D. Ang, J. Lund And F. STEnger, Complex variable and regularization methods of inversion of the Laplace transform, Mathematics of computation, 53, 188, (1989), 589-608.

[2] F. BLACK AND M. SChOles, The pricing of options and corporate liabilities, Journal of political economy, 81, 3, (1973), 637-654.

[3] H. Brunner, P. J. Davies And D. B. DunCan, Discontinuous Galerkin approximations for Volterra integral equations of the first kind, IMA journal of numerical analysis, 29, 4, (2009), 856-881.

[4] P. CARR AND L. WU The finite moment log stable process and option pricing, The journal of finance, 58, 2, (2003), 753-777.

[5] A. CARTEA AND D. DEL-CASTILlo-NegRete, Fractional diffusion models of option prices in markets with jumps, Physica A: Statistical Mechanics and its Applications, 374, 2, (2007), 749-763.

[6] A. CARTEA, Derivatives pricing with marked point processes using tick-by-tick data, Quantitative Finance, 13, 1, (2013), 111-123.

[7] M. CAPUTO, Elasticita de dissipazione, Zanichelli, Bologna, Italy, (Links), SIAM journal on numerical analysis, (1969).

[8] W. Chen, X. XU AND S. ZHU, Analytically pricing European-style options under the modified BlackScholes equation with a spatial-fractional derivative, Quarterly of Applied Mathematics, 72, 3, (2014), 597-611.

[9] W. CHEN, X. XU AND S. ZHU, Analytically pricing double barrier options based on a time-fractional Black-Scholes equation, Computers \& Mathematics with Applications, 69, 12, (2015), 1407-1419.

[10] W. CHEN, X. XU AND S. P. ZHU, A predictor-corrector approach for pricing American options under the finite moment log-stable model, Applied Numerical Mathematics, 97, (2015), 15-29.

[11] J. D. Cole, On a quasi-linear parabolic equation occurring in aerodynamics, Quarterly of applied mathematics, 9, 3, (1951), 225-236.

[12] C. Cunha AND F. VILOCHE, The Laguerre functions in the inversion of the Laplace transform, Inverse Problems, 9, 1, (1993).

[13] P. J. Davies And D. B. Duncan, Stability and convergence of collocation schemes for retarded potential integral equations, SIAM journal on numerical analysis, 42, 3, (2004),1167-1188. 
[14] A. Ali Elbeleze, A. Kilicman And B. M. TAib, Homotopy perturbation method for fractional Black-Scholes European option pricing equations using Sumudu transform, Mathematical Problems in Engineering, (2013).

[15] R. GORENFLO AND F. MAINARDI, Fractals and fractional calculus in continuum mechanics, Springer, (1997), 223-276.

[16] G. Hariharan, S. Padma and P. Pirabaharan, An efficient wavelet based approximation method to time fractional Black-Scholes European option pricing problem arising in financial market, Applied Mathematical Sciences, 7, 69, (2013), 3445-3456.

[17] E. Hope, The partial differential equation $u t+u u x=\mu x x$, Communications on Pure and Applied mathematics, 3, 3, (1950), 201-230.

[18] G. JumARIE, Stock exchange fractional dynamics defined as fractional exponential growth driven by (usual) Gaussian white noise. Application to fractional Black-Scholes equations, Insurance: Mathematics and Economics, 42, 1, (2008), 271-287.

[19] G. JUMARIE, Derivation and solutions of some fractional Black-Scholes equations in coarse-grained space and time. Application to Merton's optimal portfolio, Computers \& mathematics with applications, 59, 3, (2010), 1142-1164.

[20] S. Kumar, D. KumAR AND J. Singh, Numerical computation of fractional Black-Scholes equation arising in financial market, Egyptian Journal of Basic and Applied Sciences, 1, (3-4), (2014), 177-183.

[21] M. N. LeOnenko, M. M. MeERschaert AND A. SikorSKit, Fractional pearson diffusions, Journal of mathematical analysis and applications, 403,2, (2013), 532-546.

[22] M. LopeZ-FERnANDEZ AND C. PALENCIA, On the numerical inversion of the Laplace transform of certain holomorphic mappings, Applied Numerical Mathematics, 51,(2-3), (2004), 289-303.

[23] W. LI, The numerical solution of fractional order equation in financial models and its application, Hangzhou University of Electronic Science and Technology, Master's thesis, (2009).

[24] J. Liang, J. WANG, W. Zhang, W. QiU And F. Ren, Option pricing of a bi-fractional BlackMerton-Scholes model with the Hurst exponent H, Applied Mathematics Letters, 23, 8, (2010), 859863.

[25] F. LiU, V. ANH AND I. TURNER, Numerical solution of the space fractional Fokker-Planck equation, Journal of Computational and Applied Mathematics, 166, 1, (2004), 209-219.

[26] F. LiU, P. ZHUANG, I. TURNER, V. ANH AND K. BURRAGE, A semi-alternating direction method for a 2-D fractional FitzHugh-Nagumo monodomain model on an approximate irregular domain, Journal of Computational Physics, 293, (2015), 252-263.

[27] F. Liu, P. Zhuang, I. Turner, K. Burrage and V. Anh, A new fractional finite volume method for solving the fractional diffusion equation, Applied Mathematical Modelling, 38, (15-16), (2014), 3871-3878.

[28] Q. Liu, F. Liu, Y. T. Gu, P. Zhuang, J. Chen And I. Turner, A meshless method based on Point Interpolation Method (PIM) for the space fractional diffusion equation, Applied Mathematics and Computation, 256, (2015), 930-938.

[29] J. M. Manale, F. M. Mohomed and J. Banasiak, A simple formula for valuing American and European call and put options, Proceeding of the Hanno Rund workshop on the differential equations, University of Natal, 2000.

[30] M. M. MEERSCHAERT AND A. SiKORS KII, Stochastic models for fractional calculus, 43, (2012).

[31] R. C. MERTON, Theory of rational option pricing, The Bell Journal of economics and management science, (1973), 141-183.

[32] G. M. Mittag-Leffler, Sur la nouvelle fonction E $\alpha$ (x), CR Acad. Sci. Paris, 137, 2, (1903), 554-558.

[33] A. PAZY, Semigroups of linear operators and applications to partial differential equations, Springer Science \& Business Media, 44, (2012).

[34] D. Sheen, I. H. Sloan And V. Thomee, A parallel method for time discretization of parabolic equations based on Laplace transformation and quadrature, IMA Journal of Numerical Analysis, 23, 2, (2003), 269-299.

[35] A. TALBOT, The accurate numerical inversion of Laplace transforms, IMA Journal of Applied Mathematics, 23, 1, (1979), 97-120.

[36] M. UdDin, H. Ali AND A. Ali, Kernel-based local meshless method for solving multi-dimensional wave equations in irregular domain, CMES-COMPUTER MODELING IN ENGINEERING \& SCIENCES, 107, 6, (2015), 463-479.

[37] M. UdDin, Z. Minullah And A. Ali, On the approximation of rapidly oscillatory Hankel transform via radial kernels, Dolomites Research Notes on Approximation, 11, 1, (2018), 29-36.

[38] M. UdDin, KAMRAN AND A. ALI, A localized transform-based meshless method for solving time 
fractional wave-diffusion equation, Engineering Analysis with Boundary Elements, 92, (2018), 108113.

[39] M. UdDIN AND S. HAQ, RBFs approximation method for time fractional partial differential equations, Communications in Nonlinear Science and Numerical Simulation, 16, 11, (2011), 4208-4214.

[40] W. Wyss, The fractional Black-Scholes equation, Fractional Calculus and Applied Analysis, 3, (2017), 51-62.

[41] P. ZhuAng, F. LiU, V. ANH AND I. TuRner, New solution and analytical techniques of the implicit numerical method for the anomalous subdiffusion equation, SIAM Journal on Numerical Analysis, 46, 2, (2008), 1079-1095.

[42] P. Zhuang, F. Liu, V. Anh And I. Turner, Numerical methods for the variable-order fractional advection-diffusion equation with a nonlinear source term, SIAM Journal on Numerical Analysis, 47, 3, (2009), 1760-1781.

[43] P. ZhuAng, F. LiU, I. Turner And Y. T. GU, Finite volume and finite element methods for solving a one-dimensional space-fractional Boussinesq equation, Applied Mathematical Modelling, 38, (1516), (2014), 3860-3870.

[44] F. Zeng, F. LiU, C. Li, K. Burrage, I. Turner And V. AnH, A Crank-Nicolson ADI spectral method for a two-dimensional Riesz space fractional nonlinear reaction-diffusion equation, SIAM Journal on Numerical Analysis, 52, 6, (2014), 2599-2622.

[45] M. Zheng, F. LiU, I. TURNER AND V. ANH, A novel high order space-time spectral method for the time fractional Fokker-Planck equation, SIAM Journal on Scientific Computing, 37, 2, (2015), 701-724.

[46] H. Zhang, F. LiU, I. Turner And Q. YAng, Numerical solution of the time fractional BlackScholes model governing European options, Computers \& Mathematics with Applications, 71, 9, (2016), 1772-1783. 